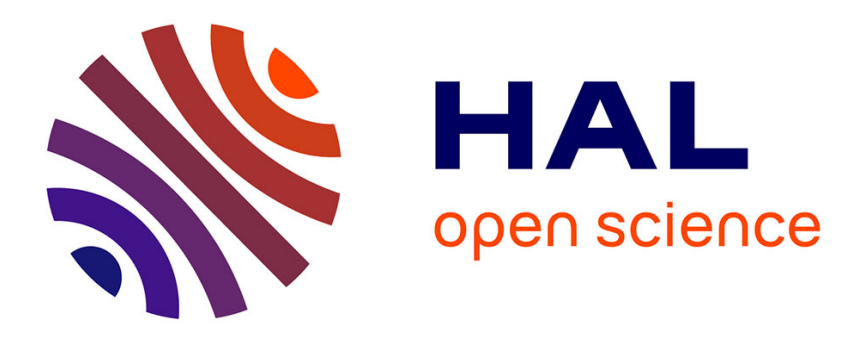

\title{
Diffusion bonding of hardmetals (WC-Co) with metallic interlayers
}

\author{
J.M. Gómez de Salazar, A. Ureña
}

\section{To cite this version:}

J.M. Gómez de Salazar, A. Ureña. Diffusion bonding of hardmetals (WC-Co) with metallic interlayers. Journal de Physique IV Proceedings, 1993, 03 (C7), pp.C7-1093-C7-1098. 10.1051/jp4:19937171. jpa-00251801

\section{HAL Id: jpa-00251801 https://hal.science/jpa-00251801}

Submitted on 1 Jan 1993

HAL is a multi-disciplinary open access archive for the deposit and dissemination of scientific research documents, whether they are published or not. The documents may come from teaching and research institutions in France or abroad, or from public or private research centers.
L'archive ouverte pluridisciplinaire HAL, est destinée au dépôt et à la diffusion de documents scientifiques de niveau recherche, publiés ou non, émanant des établissements d'enseignement et de recherche français ou étrangers, des laboratoires publics ou privés. 


\title{
Diffusion bonding of hardmetals (WC-Co) with metallic interlayers
}

\author{
J.M. GÓMEZ DE SALAZAR and A. UREÑA \\ Dpto. Ciencia de los Materiales e Ingeniería Metalúrgica, Facultad de Ciencias Químicas, Universidad \\ Complutense de Madrid, 28040 Madrid, Spain
}

\begin{abstract}
Diffusion bonding of hardmetals (WC-Co) to themselves or with other metallic material (mildsteel) has been evaluated in the present paper. Metallographic studies and mechanical tests have been used to determinate the influence of the bonding parameters (temperature, pressure and time) on the bond microstructure and strength. Different metallic interlayers applied in form of thick foils were used (nickel, nickel-copper and stainless steel). Special interest was dedicated to the solid state reactions occurred in the bond interfaces.
\end{abstract}

\section{INTRODUCTION}

Actually, the increase in the use of materials which present an elevated hardness and, consequently, a high wear resistance is doing that cemented carbides (hardmetals) have significant applications as coating materials projected by plasma spray or HVOH techniques (1).

These materials must be joined to others like tools steels used in the automotive industries (metal-cutting, dies, punches or valves) however the different thermal stresses and demagage to microstructure in hardmetals rules out the possibility of using fusion welding techniques. Normally, these materials are joined by brazing processes (2), but its poor thermal and corrosion resistance make necessary to develop another bonding techniques similar to diffusion bonding (3). It minimizes handicaps similar to: fumes (brazing), thermal stresses, microstructural alteration, metallurgical and chemical incompatibilities, etc, which are usual in fusion welding processes.

In the present investigation, we have studied by metallographic techniques and mechanical test, the application of diffusion bonding to the joint of hardmetals and of they with a mild steel using ductile interlayers as $\mathrm{Ni}$, or and $\mathrm{Cu}$ and stainless steel (AISI 304). The process described in this paper has been carried out for different conditions marked in the bibliography $(4,5)$, in order to obtain a competitive joint process for the industries. 


\section{MATERIALS AND PROCEDURE}

\subsection{Materials.}

Materials used in the present investigation were:

- Hardmetal is constituted principally by WC particles with idiomorphic form and cobalt (Co) as binder. Its composition is $85 \mathrm{wt} \%$. of WC and $15 \mathrm{wt} \%$ of Co. The grain size of WC particles are between 3 and $6 \mu \mathrm{m}$ (Co has been removed by metallografic etching) (Fig.1). Specimens used in the present work were cylinders $\left(10 \mathrm{~mm} \phi\right.$ and $25 \mathrm{~mm}$ long) and parallelopipeds $\left(5,3 * 6,5 * 21 \mathrm{~mm}\right.$ and $\left.10^{*} 10^{*} 25 \mathrm{~mm}\right)$ for mechanical tests; and cylinders of $10^{* 10} \mathrm{~mm}$ for metallographic studies.

- Steel is an ASTM 1045 with serni-hard denomination. It has a chemical composition (\% wt.) of: 0.45 $\mathrm{C}, 0.55 \mathrm{Mn}$ and $<0,22 \% \mathrm{Si}$. Samples were cylinders $(10 \mathrm{~mm} \phi$ and $25 \mathrm{~mm} \mathrm{long})$ obtained by cutting of a calibrated bar. Its microstructure is principally constituted by proeutectoid ferrite grains in elongated form and perlite, which can not be resolved by optical microscopy (Fig.2).

- Bonding interlayers used were foils of $\mathrm{Ni}$ and $\mathrm{Cu}$, and a stainless steel (AISI 304). All of them were cold rolled in order to obtain foils with thickness in the range of 0.05 and $0.08 \mathrm{~mm}$.

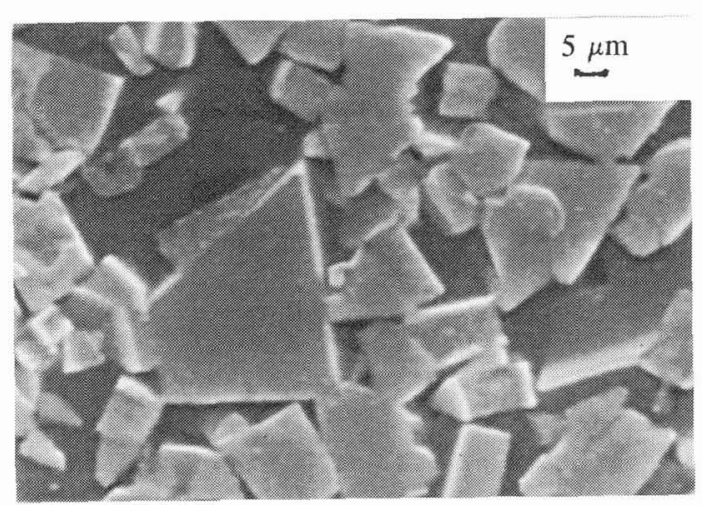

Fig.1.- WC-15\%Co microstructure, constituted by idiomorphic WC grains and Co as binder.

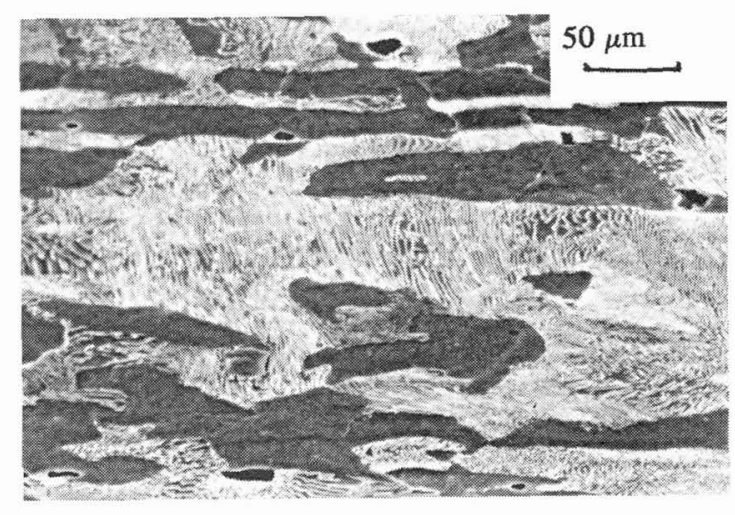

Fig.2,- ASTM 1045 microstructure, ferrite grains and perlite.

\subsection{Sample preparation.}

All surfaces were grinding in emery paper of $320,400,600$ and 1200 grades. Hardmetal surfaces (HD) were finally polished with diamond past of $3 \mu \mathrm{m}$ size, using nylon cloth and lubricated with etilenglicol. All specimens were washed with absolute alcohol or acetone in an ultrasonic bath. With this surface preparation, the roughness obtained were in the range of 0.07 to $0,1 \mu \mathrm{m}$.

\subsection{Bonding conditions.}

Diffusion bonding of these materials were carry out in an experimental vacuum furnace described in previous papers (6), according with the following conditions: temperatures between 1173 and $1373 \mathrm{~K}$, bonding pressures lower than $15 \mathrm{MPa}$ in order to prevent a macrodistortion higher than $5 \%$ in the steel, times of 30,60 and 120 minutes and a vacuum between $10^{-1}$ and $10^{-2} \mathrm{~Pa}$. These materials were diffusion bonded for metallographic studies or mechanical bend test. 


\section{RESULTS AND DISCUSSIONS.}

\subsection{Metallographic studies of the bonding interfaces.}

\subsection{1. $\mathrm{HD} / \mathrm{Ni}$ interface.}

Optical microscopical studies of the HD/Ni interface show evidences of solid state reaction between hardmetal and Ni interlayer (Fig. 3). When this interface is observed at higher magnifications by SEMEDS techniques (Fig. 4), WC particles appear in a rounded form in zones colsed to Ni interlayer by dissolution effect. This fact is a clear evidence of the reaction between both constituents (WC-Co and $\mathrm{Ni}$ ). The WC decomposition by Ni promotes the diffusion of $\mathrm{W}$ and $\mathrm{C}$ through the interlayer forming, in a first steep, a solid state solution constituted by W, Co and Ni. Carbon, insoluble in Ni interlayer (7), and unreactioned free tungsten react forming again WC which precipitates in solid state into Ni interlayer (particles marked A in Figure 4). EDS microanalysis carried out in $\mathrm{Ni}$ interlayer at different distances from the interface shown the presence of Co and W $(7 \% \mathrm{~W}$ and $12 \%$ Co at $1 \mu \mathrm{m}$, and $1.2 \% \mathrm{~W}$ and $5.4 \% \mathrm{Co}$ at $20 \mu \mathrm{m}$ ). Ni was detected in Co binder with contents between $17.6 \%$ at $1 \mu \mathrm{m}$ and $1.6 \%$ at $30 \mu \mathrm{m}$ from the interface.

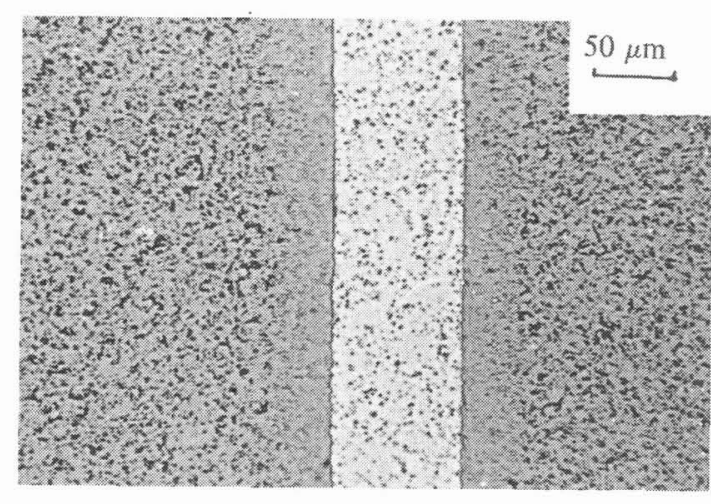

Fig.3.- HD/Ni/HD diffusion bonding interface.

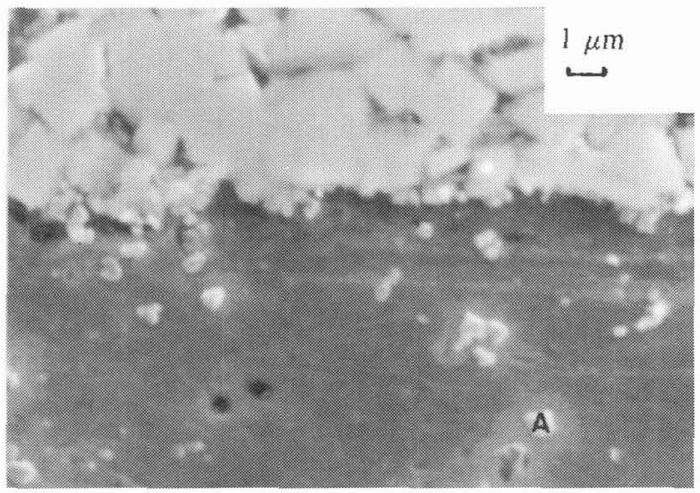

Fig.4.- HD/Ni interface: WC grains rounded as consequence of the reaction between $\mathrm{WC}$ and $\mathrm{Ni}$ in solid state.

\subsubsection{HD/AISI 304 interface.}

Optical microscopy shows the formation of a narrow zone between the hardmetal and the stainless steel (AISI 304) used as interlayer (Fig. 5). The amplitude of this zone (between $3 \mu \mathrm{m}$ and $6 \mu \mathrm{m}$ ) depends on the bonding conditions. At higher magnification, WC particles appear rounded and fragmented (Fig. 6). These facts are consequence of solid state reactions between the present constituents. The dissolution process of WC promote the diffusion of all elements involved $(\mathrm{C}, \mathrm{Cr}, \mathrm{Fe}, \mathrm{Co}$ and $\mathrm{Ni})$. When the temperature decrease, these elements precipitate in a tungsten solid solution, forming this reaction zone. EDS microanalysis shown a complex spectrum which correspond with the next quantitative composition (in wt \%): $5.5 \mathrm{Cr}, 10.6 \mathrm{Fe}, 4.7 \mathrm{Co}, 0.95 \mathrm{Ni}$ and $78.0 \mathrm{~W}$. As final conclusion, it can deduced that the formation of this reaction zone, between hardmetal and the AISI 304 could give a poor bond strength. 


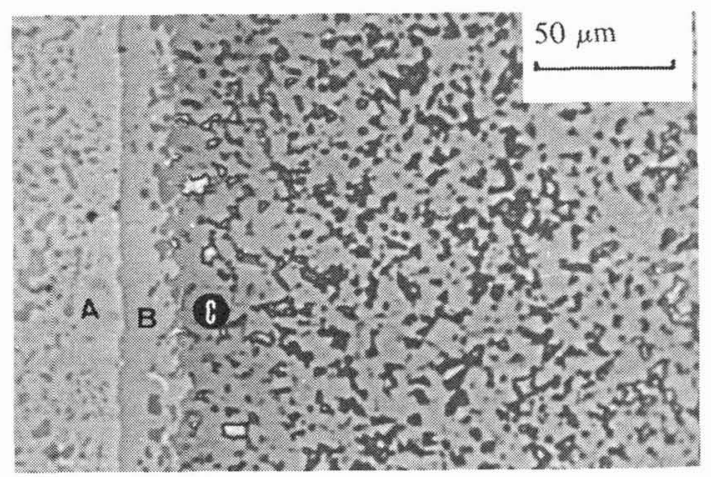

Fig.5.- HD/AISI 304 interface observed by optical microscopy. A) AISI; B) reaction zone and C) Hardmetal.

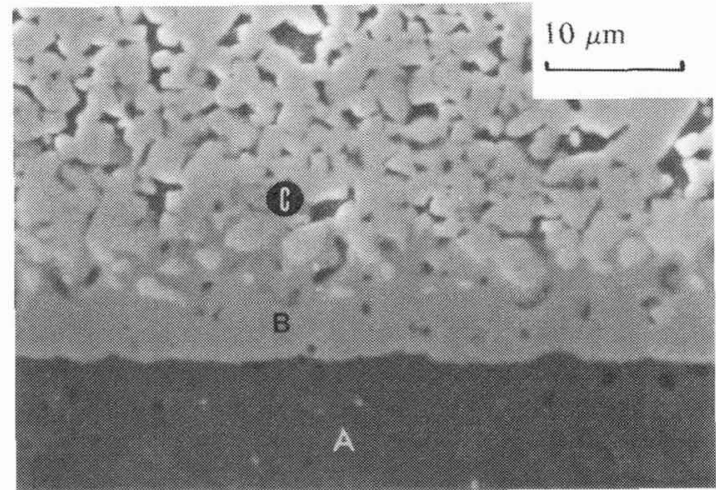

Fig.6.- A) AISI 304; B) reaction zone, WC particles in rounded form; C) Hardmetal.

\subsubsection{Ni/Mild Steel (MS) interface.}

The complete intersolubility of $\mathrm{Ni}$ and $\tau$-Fe at bonding temperature favours the interdiffusion of both elements. When the joint is cooled the solubility of these constituents in solids state decrease (7). For this reason, iron precipitates both in grain boundaries and $\mathrm{Ni}$ grains ( $\mathrm{A}$ in Fig. 7). The high contents of $\mathrm{Ni}$ dissolved in iron make stable the $\tau$-Fe (Austenite) at low temperature (8). It explains the formation of an austenite layer (marked with discontinuous trace in figure 7). The Ni composition in this zone has a maximum of $15 \mathrm{wt} \%$.

During cooling cycle the steel, in austenite form, is transformed in proeutectoid ferrite ( $\mathrm{Fe}_{\mathrm{cc}}$ ) and perlite (Fig. 7). Perlite nucleations is preferentially in austenite/austenite interfaces (8). For this reason, cementite plates appear on austenite in parallel way. This transformation has place in this steel at approximately 1070 K (9) (Fig. 7).

\subsection{4. $\mathrm{Cu} / \mathrm{Mild}$ Steel (MS) interface.}

Figure 8 shows the $\mathrm{Cu} / \mathrm{MS}$ interface constituted by ferrite (A), perlite (B) and $\mathrm{Cu}(\mathrm{C})$. The presence of dark precipitates (A in Fig. 9) in the interface is due to the existence of oxygen in the first steeps of the bonding process. Iron reacted with oxygen forming an oxide, which has been analyzed by EDS as Wustite (FeO) with copper in solid solution. In this figure we can observed the $\mathrm{Ni} / \mathrm{Cu}$ interface, that present Kirkendall porosity. Copper precipitates in ferrite grain boundaries have been detected as consequence of low solubility of both elements at room temperature (Fig. 9), (9).

\subsection{Mechanical testing and fractography.}

\subsection{1.- Bending test.}

Specimens were tested in a 3-point bend rig with outer loading points set at a distance of $30 \mathrm{~mm}$. The strength was calculated according ISO 3327 using samples bonded without final mechanizing. It means that surface defects are present (critical conditions).

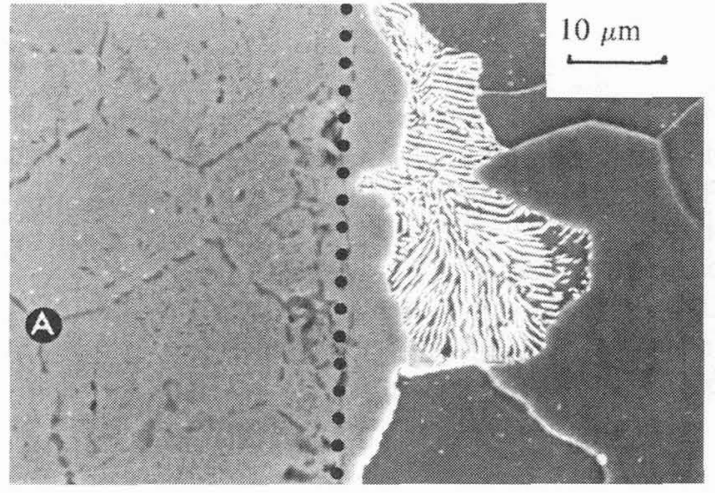

Fig.7.- Hardmetal/MS interface: A) Iron precipitates both in grain boundaries and $\mathrm{Ni}$ grains. 


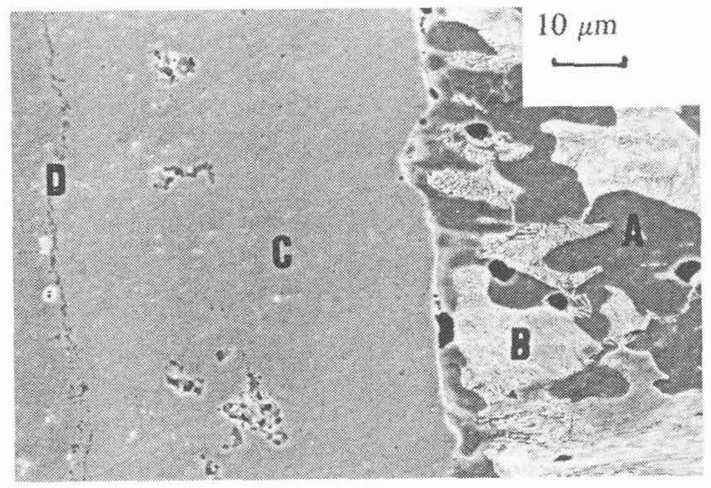

Fig. 8.- Ni-Cu/MS interface:A) Ferrite; B) Perlite; C) $\mathrm{Cu}$; D) $\mathrm{Ni} / \mathrm{Cu}$ interface (Kirkendall porosity).

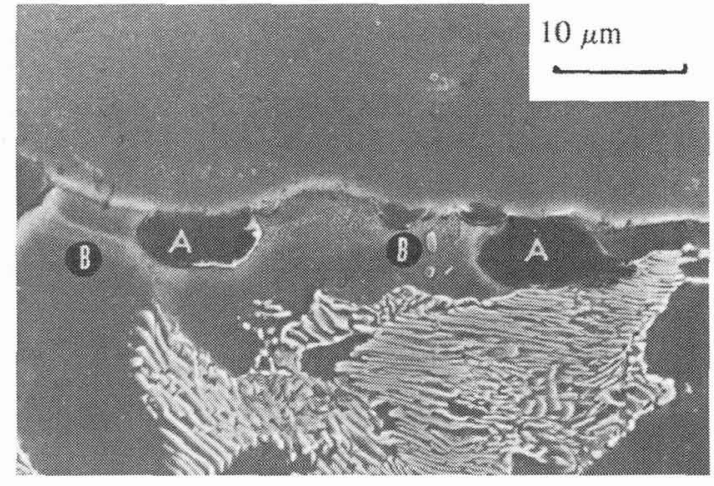

Fig.9.- Cu precipitates both in grain boundaries and ferrite grains. (B)

Hardmetal parent materials used in this research have an average bend strength of $2430 \mathrm{MPa}$. When the hardmetals is heated with a thermal cycle similar bonding one, there is a light strength (6\%). If a similar defect $(0.2 \mathrm{~mm}$ thick and $0.6 \mathrm{~mm}$ depth notch) is made on the hardmetal surface by cutting with a diamond disk, its bend strength decrease approximately in $60 \%$ in relation with the parent hardmetals.

The average bend strength of HD/Ni/HD joints obtained from samples bonded with an area of $32 \mathrm{~mm}^{2}$ at $1373 \mathrm{~K}$ and $10 \mathrm{MPa}$ was $1155 \mathrm{MPa}$. A fact deduced of this study is that the bonding time has not a significant effect in the strength bond. When the area is increased to $100 \mathrm{~mm}^{2}$ and the bonding pressure is $15 \mathrm{MPa}$ for the same temperature, the average bend strength decreases to $800 \mathrm{MPa}$. The increase of bonding pressure does not balance the notch effect generated during the surface preparation of the specimens (6). This fact has a negative effect during bending test.

The bend strength HD/AISI/HD joints decreases in relation with previous joint. It was observed that bonding load plays an important role in the bond strength and compensates, in part, the surface parallelism default, obtaining higher strength $(275 \mathrm{MPa})$ when bonding pressure was $15 \mathrm{MPa}$. This value decreased $(170 \mathrm{MPa})$ when bonding pressure was reduced $(10 \mathrm{MPa})$.

Figure 10 shown the strength values obtained from cylinders of $\mathrm{HD} / \mathrm{Ni} / \mathrm{MS}$ and $\mathrm{HD} / \mathrm{Ni} / \mathrm{Cu} / \mathrm{MS}$ diffusion bonds. This graphic representation shows again that bonding time has not an important influence as these diffusion tests. The bonding conditions used were temperature of $1173 \mathrm{~K}$ and pressure of $5 \mathrm{MPa}$.

\subsubsection{Fractography.}

Broken surfaces were studied by SEM at low and high magnifications in order to deduce the fracture mechanisms that have place in the bond failure. In figure 11 are shown the five possible mechanisms of the crack progression during bend test. When the rupture has place through the interlayer ( $\mathrm{Ni}, \mathrm{steel}, \mathrm{Cu}$ or $\mathrm{Ni} / \mathrm{Cu}$ interface) its fracture is ductile (Fig. 12), but when it is through hardmetal, it appears with a typical brittle surface (Fig. 13).

\section{CONCLUSIONS.}

1.- The viability of $\mathrm{Ni}, \mathrm{Ni} / \mathrm{Cu}$, AISI 304 as interlayers in diffusion bonding of hardmetals has been proved by metallographic and mechanical test.

2.- The notch effect present in the bond interface, originated by a deficient surface preparation, decreases the bend strength nearly to the $70 \%$. This negative effect is not compensated by the 
increase of bonding pressure.

3.- Bend strength of $\mathrm{HD} / \mathrm{Ni} / \mathrm{MS}$ ones is higher than of $\mathrm{HD} / \mathrm{Ni} / \mathrm{Cu} / \mathrm{MS}$ joints, due to the presence of Kirkendall porosity in $\mathrm{Ni} / \mathrm{Cu}$ interface.

4.- Bend strength of $\mathrm{HD} / \mathrm{Ni} / \mathrm{HD}$ joints is higher than of HD/AISI304/HD ones, because the formation of a narrow reaction zone in the HD/AISI304 interface, which makes weaker the joint.
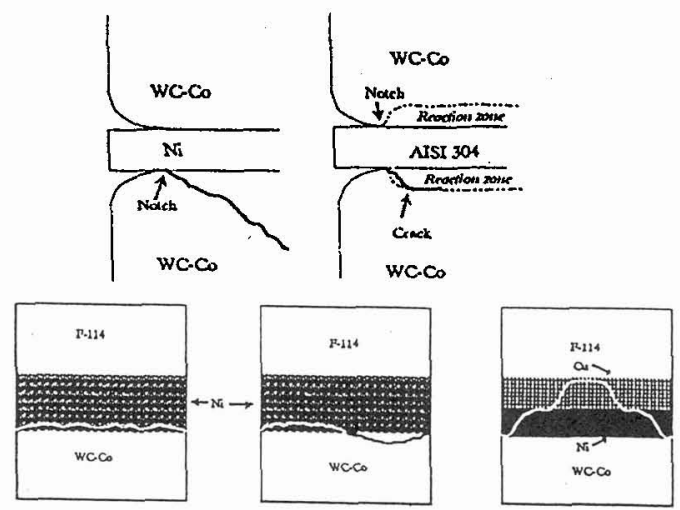

Fig.11.- Crack progression during bend test.

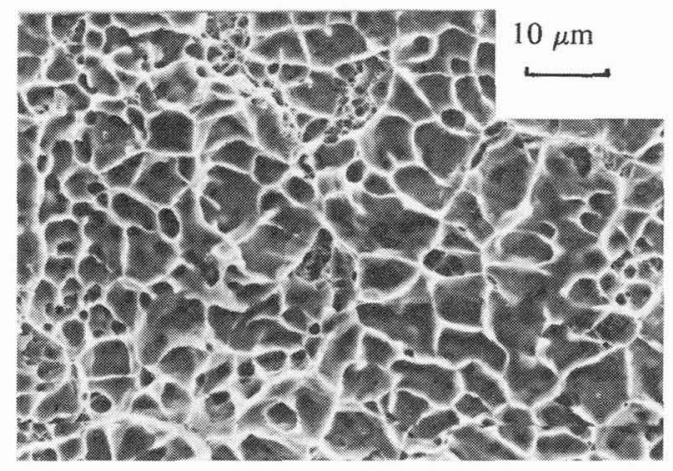

Fig. 12.- Ductile fracture of Ni interlayer.

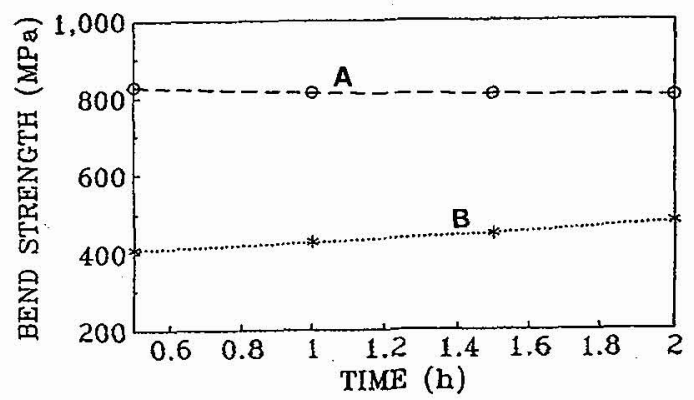

Fig.10.- Bend Strength/Time representation: A) $\mathrm{HD} / \mathrm{Ni} / \mathrm{MS}$ bond strength, B) $\mathrm{HD} / \mathrm{Ni} / \mathrm{Cu} / \mathrm{MS}$ bond strength.

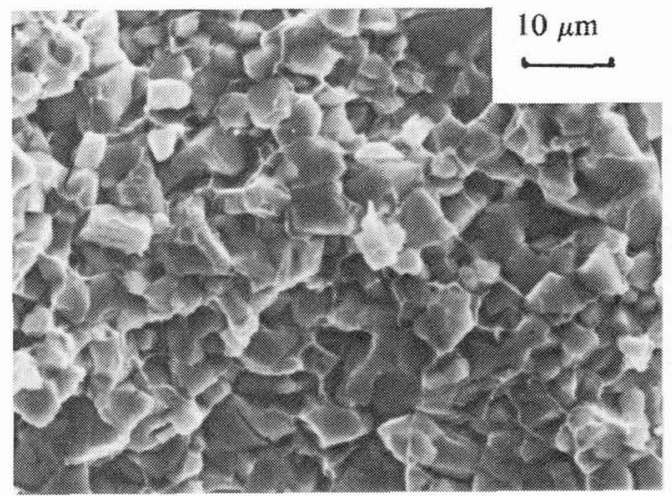

Fig.13.- Brittle fracture of WC-Co hardmetal.

\section{BIBLIOGRAPHY.}

(1) GUILEMANY J.M., PACO J.M., LLORCA N., MIQUEL J.R. $3^{\text {as }}$ Sesiones Técnicas sobre Nuevas Tecnologías de Unión. CES. Madrid. Mayo 1993.

(2) PATRIARCA P., SLAUGHTHER G.M., MANLY W.D.ORLN-2243, MARCH 1953.

(3) CALVO F., UREÑA A., GOMEZ DE SALAZAR. J.M., et al.. Rev. Soldadura, 16, (1986), 113123.

(4) COTTENDEN A.M., ALMOND E.A. Metals Technology. June, 1981, 221-232.

(5) KAZAKOV N.F.. "Diffusion Bonding of Materials". Pergamon Press, Oxford, 1985.

(6) UREÑA A., GOMEZ DE SALAZAR J.M., QUIÑONES J. J. Mater. Sci. 27,(1992), 5291-5296.

(7) MURRAY L. "Binary Phase Diagrams". ASM. Metal Park Ohio. USA. 1986.

(8) HONEYCOMBE RWK. "Steel Microstructure and Properties". Edward Arnold. London, 1982.

(9) SINHA A.K."Ferreous Physical Metallurgy". Butterworths. Boston. 1989. 